Research Note

Journal of Extension Education

Vol. 29 No. 4, 2017

DOI:https: / /doi.org/10.26725/JEE.2017.4.29.5984-5987

\title{
Attitude and Perception of Local Inhabitants towards Mangrove Ecosystems
}

\section{K. Dinesh, E.R. Chinchu ${ }^{2}$ and M.T. Geeji ${ }^{3}$}

\begin{abstract}
Conservation of the mangrove habitat is highly essential to protect the coastal regions and the livelihood of the local folk, mainly comprising fishermen community. Involvement of local inhabitants is the key factor for the success of all ecosystem conservation activities. In the present study, the attitude and perceptions of local people of Puduveypu area of Ernakulam District, Kerala towards the conservation of Mangrove ecosystem were examined. A total of 1966 respondents were surveyed. Among these, $52.3 \%$ of the villagers were positive and showed interests in the ecological importance of Mangrove ecosystems. A small group of people viewed that mangroves restrict their developmental activities and consider them as a menace. The study illustrates that it is important to inculcate a mangrove friendly lifestyle among these communities for better conservation of this ecosystem.
\end{abstract}

Keywords: Environmental awareness; Environmental education; Mangrove conservation; Kerala

Mangrove ecosystem is defined as an association of halophytic trees, shrubs, palms, vines and ferns. These plant groups have special physiological adaptations suitable for the_saline and oxygen deficient growth conditions. Most of the tropical and subtropical coastal wetlands are inhabited by mangroves, offering multiple uses (medicine, food, fire wood etc.) to the local inhabitants. This ecosystem enhances fishery of the region due to its high level of primary productivity and also can act as the coastal 'bio shield' to protect the coastal population from tsunami and other natural calamities.

It is a fact that globally mangroves have been facing severe loss at a rate of 1 to $2 \%$ per year. The remaining segments of the global mangroves are also degraded very fast. This is mainly due to the conversion of mangrove forests to agriculture, aquaculture and urban development (Giri et al., 2011). This study examines the attitude and

1. Associate Prof. and Head, 2 \& 3, Research Associates, Kerala University of Fisheries and Ocean Studies (KUFOS), Panangad P.O., Cochin, Kerala - 682506.

Received : 23-01-2018; Accepted : 03-04-2018 
perception of people towards mangrove ecosystem.

\section{METHODOLOGY}

The present study was conducted in Puduveypu area, Kochi, Kerala as part of the project entitled "Mangroves for fisheries and environmental enhancement in Cochin- a comprehensive intervention through participatory approach" funded by Science and Engineering Research Board (SERB), Government of India. The major objective of the study was to assess the knowledge level of local inhabitants residing in Puduveypu on the ecosystem services of mangroves and their perception on mangrove conservation. To have a first hand estimate about the overall public knowledge on mangrove habitat, a questionnaire survey was carried out among the local inhabitants with the help of 25 Kudumbasree Groups (bonafide groups formed under the women empowerment programme by the State Poverty Eradication Mission (SPEM) of the Government of Kerala). Altogether 1966 people were surveyed under the programme. The questions used for the survey were both semistructured and open ended, which helped to derive qualitative and quantitative information (Guba and Lincoln, 1994). The data were collected on many aspects including: 1. Personal information 2. Economic activities 3. Awareness regarding the ecological services of mangroves 4. Knowledge level on the nearest mangrove ecosystem 5. Attitude towards conservation and developmental issues. Descriptive statistics was used to summarize the data.

\section{FINDINGS AND DISCUSSION}

Among the respondents, 52.4\% came under 26 to 35 years of age group and $34.4 \%$ of the respondents are of the age group of 36 to 45 years. The comparatively young respondents (1525 years old) are less in number (6.2\%) and the elderly adults (50-70 years old) participated in the survey constituted $6.8 \%$. According to the survey, all the respondents were literate and had studies at least to the primary level. 59.4\% had completed their graduation while the highest level of education was Post Graduation (21.6\%). Daily labour (52.9\%) and small scale business (13.1\%) were the major livelihood agenda for the local communities. The average land holding size was about 4 to 20 cents. Families which have the land area of more than 40 cents were very less. The average monthly income of the respondents ranged between Rs. 5000/and Rs. 9000/-.The data show that all the households had mangrove plants in their premises. Ample percentage of the households (65.3\%) had high density of mangrove plants with more than one species in their premises. This shows that people who have good understanding on the ecological importance of mangrove ecosystem is very low in number $(7.5 \%)$. The proportion of respondents who had heard about the ecological services of 


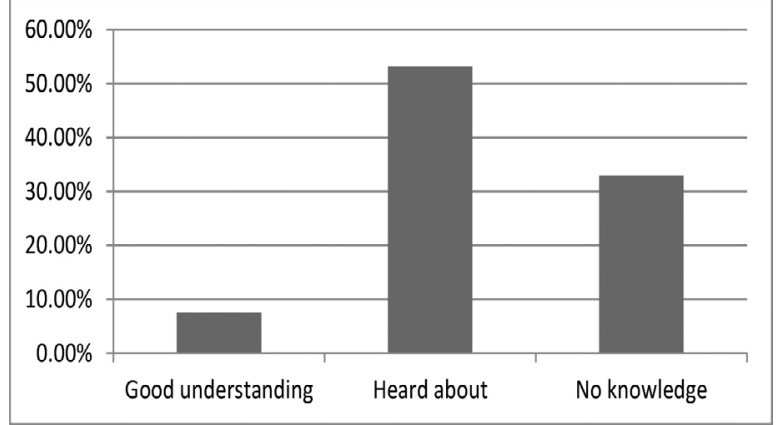

Fig.1: Ecological services

mangroves was $53.2 \%$. Percentage of the inhabitants who are ignorant on this aspect was $33 \%$. Only $7.5 \%$ of the respondents were well educated in this area (Fig.1). 51.9\% of the respondents had reported that they had heard about the mangrove ecosystem. Only 4.9\% of them do know about the mangrove ecosystem near their premises (Fig.2). In general, the respondents were not

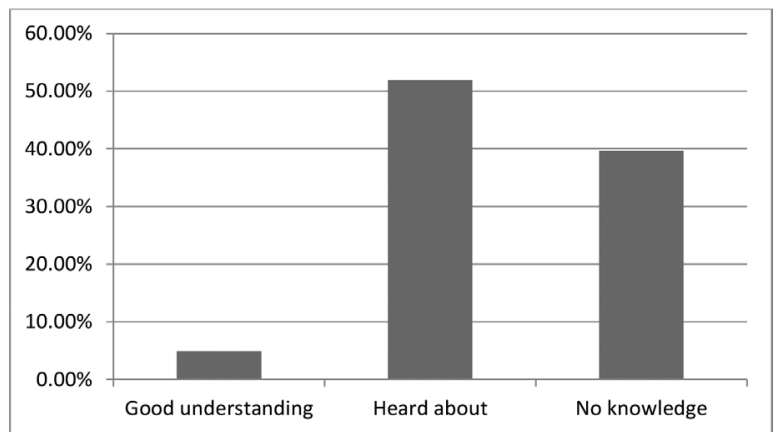

Fig.2 : Knowledge on mangroves

much skilful in identifying mangrove plants from other coastal vegetation. Among the total respondents, 39.7\% felt that mangrove vegetation nearby their premises was a nuisance and restrict the developmental activities(Fig.3). It is also noted that the people living near the mangrove ecosystem of Puduveypu were not directly using these plants in their day to day life. But the elderly people reported that they had used mangroves as fire wood and house construction materials in their early ages.

Success of all ecosystem restoration programmes always depend upon the community participation. Social and ecological systems should be linked scientifically for better sustainable conservation programmes. The current study clearly shows Puduveypu area is rich in mangroves but the inhabitants of the region are not well aware about the ecological importance of these ecosystems. All the inhabitants have either true mangroves or mangrove associates within

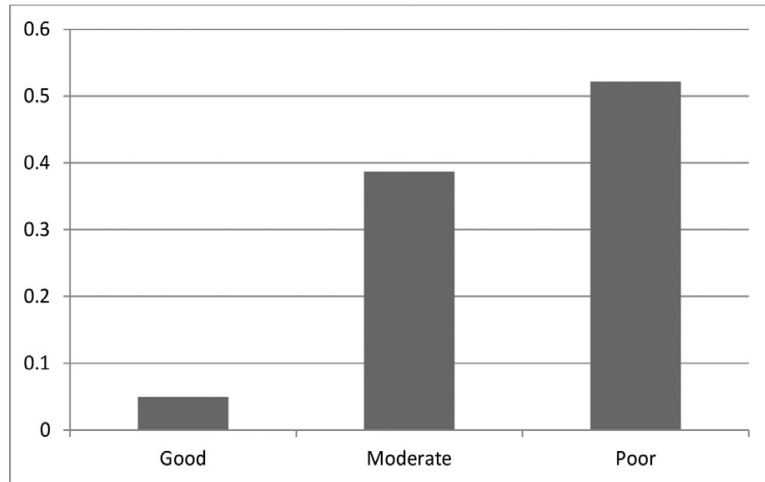

Fig.3 : Ability to differentiate mangroves from other coastal plants

their house premises but their expertise in identifying the plants to species level remains minimal. In general, the people of the area including the educated class are not keen about the conservation need of mangroves. This highlights the need of improved environmental education. 
Hence, the negative attitude of the inhabitants of the Puduveypu mangrove ecosystem could be attributed to the lack of direct benefits from this ecosystem. This issue may be addressed with due care by implementing various awareness programmes by the scientific community, planners and policy makers.

It is a proven fact that the relationships between coastal communities and their environment are complex and it is essential to gain the support from the rural communities who live adjacent to every ecosystem for the successful ecosystem management. Therefore, in order to attain the sustainable local support for the conservation projects, the attitude and perception of different classes of people towards the specific ecosystem need to be understood. From the current study on the attitude and perceptions of the local inhabitants of Puduveypu towards the mangrove ecosystem, it is concluded that most of the respondents showed positive attitude towards the need of awareness programme on the ecological importance of mangrove ecosystem. The planners and policy makers may look into the fact that so long as the cost of ecosystem conservation is more expensive than the benefits from that ecosystem, it may gradually bring down the people's interest and participation. All the conservation programmes on environment should be designed in such a way that adequate care is given to facilitate the sustainable utilization of the resource potential.

\section{REFERENCES}

Giri, C.,E. Ochieng, L.L. Tieszen, Z. Zhu, A.Singh, T. Loveland, J. Masek, \& Duke N. (2011). Status and distribution of mangrove forests of the world using earth observation satellite data. Global Ecology and Biogeography 23:154-159

Guba, E.G. \& Lincoln, Y.S. (1994). Competing paradigms in qualitative research. In: Denzin, N.K. \& Lincoln, Y.S. (Eds.), Handbook of Qualitative Research. Sage, London, pp. 105-117.

McClanahan, T.R., Maina, J., \& Davies, J., (2005). Factors influencing resource users and managers' perceptions towards marine protected area management in Kenya. Environmental Conservation 32 (1): 4249.

Patton, M.Q. (1990). Qualitative Evaluation and Research Methods, Sage, Newbury Park, California, 532 pp. 